\title{
Apartidarismo e racionalidade: a relação entre os novos eleitores independentes e os partidos políticos sob a perspectiva da mobilização cognitiva
}

Éder Rodrigo Gimenes'

DALTON, R. J. The apartisan American: dealignment and changing electoral politics. Washington, DC: Sage, 2013. 209 p.

Russell J. Dalton, professor de Ciência Política da University of California, se dedica aos estudos sobre a cultura política desde a década de 1980, com destaque ao eleitorado norte-americano e de democracias consolidadas. Além de diversos artigos, escreveu e organizou importantes obras, algumas delas em parceria, como "Parties without partisans" (2001), "The good citizen" (2007), "Citizen politics: public opinion and political parties in advanced industrial democracies" (2008), "Citizens, context, and choices" (2011) e "Political parties and democratic linkage" (2011). Recentemente, tem escrito sobre o desalinhamento partidário nos Estados Unidos (DALTON 2013, 2014a) e na Alemanha (DALTON, 2014b, 2014c).

Em seu mais recente livro, intitulado "The apartisan American: dealignment and changing electoral politics", Dalton se dedicou à análise de um fenômeno amplamente evidenciado pela Ciência Política contemporânea: o distanciamento crescente entre eleitores e partidos políticos. Dividida em dez

Atualmente cursa Doutorado em Sociologia Política na Universidade Federal de Santa Catarina (UFSC). Mestre em Ciências Sociais pela Universidade Estadual de Maringá (UEM). Pesquisador dos grupos de pesquisa "Cultura Política, Comportamento e Democracia" (UEM/CNPq) e "Núcleo de Pesquisa em Movimentos Sociais" (NPMS - UFSC/CNPq) e do "Núcleo de Pesquisas em Participação Política" (NUPPOL - UEM)

E-mail:ergimenes@uem.br. 
capítulos, a obra foi conduzida sob a perspectiva empírica de discussão da relação entre os indivíduos norte-americanos e as referidas instituiçóes democráticas. No entanto, cabe destaque ao capítulo em que extrapolou sua metodologia analítica ao contexto europeu, cujos resultados apresentam convergência com aqueles identificados entre os eleitores dos Estados Unidos.

Um ponto-chave para o entendimento da relevância da obra é analisá-la à luz de "Political parties and democratic linkage", livro em que Dalton, em parceira com David Farrell e Ian McAllister, abordou a discussão em torno da manutenção ou decadência da importância dos partidos políticos entre o eleitorado, ainda que considerado um gap entre tais atores políticos. Nesse sentido, os capítulos iniciais de "The apartisan American: dealignment and changing electoral politics" apresentam ao leitor o estado da arte da temática discutida. O autor problematiza o cenário político norte-americano a partir da constatação de que nas últimas cinco décadas verificou-se uma elevação substancial de eleitores não partidários. Este é um dado relevante, principalmente se considerarmos que a identificação partidária é o eixo para a compreensão moderna da democracia eleitoral e, também, do comportamento eleitoral - posição central que provavelmente se manterá ao longo do tempo. Apesar de tal enfraquecimento, estudos anteriores apontaram que o partidarismo ainda se constitui no mais forte preditor da escolha do voto, o que justifica tanto a preocupação com a temática quanto o estudo do fenômeno. O autor dialoga com argumentos decorrentes das teorias do pós-materialismo (INGLEHART, 1977) e da cidadania crítica (NORRIS, 1999, 2007), cuja perspectiva de distanciamento dos eleitores com relação aos partidos é vista de maneira otimista, uma vez que interpreta o fenômeno como sinal de aumento da qualidade da democracia.

Na sequência da obra, é apresentado o conceito central de "The apartisan American", o qual consiste na definiçáo de diferentes perfis de eleitores a partir de uma combinação de três diferentes variáveis: escolaridade e interesse por política, agregadas em um índice de mobilizaçáo cognitiva, e simpatia partidária. Em uma escala crescente de sofisticação em termos de cultura política e comportamento eleitoral, Dalton classifica os eleitores em: independentes apolíticos, partidários rituais, partidários cognitivos e apartidários.

Definidos os perfis do eleitorado, o autor dedica parte considerável da obra à identificação de características concernentes aos diferentes eleitores por 
meio de discussóes e de análises empiricamente orientadas. Tendo como pressuposto a afirmação de que o envolvimento em campanhas e eleiçóes pode melhorar o conhecimento dos indivíduos sobre política e seu sentimento de eficácia política, Dalton identifica, com base na pesquisa eleitoral referente à campanha presidencial de 2008 empreendida pela "American National Election Studies (ANES)", que a relação estabelecida pelos eleitores com os partidos (identidade partidária), moderada pela medida de mobilizaçáo cognitiva, influencia os cidadãos a buscarem informação política, bem como conhecimento político (em termos de compreensão e retenção de informaçóes políticas e de efetividade da participaçáo dos indivíduos em questôes relacionadas ao tema) e na adesão à democracia.

Considerando o argumento de que o nível de participação política é, inevitavelmente, um sinal de vitalidade da democracia, o autor busca, também, identificar o perfil dos ativistas políticos norte-americanos em termos de participação eleitoral, atividades de campanha, açóes diretas não eleitorais, protesto (por meio de assinaturas de petiçóes, compra ou boicote de produtos por razóes políticas ou éticas, doação de recursos a grupos não partidários, estabelecimento de contato com políticos etc.) e cyberativismo. De modo geral, os resultados empíricos confirmam o argumento teórico do autor. Assim, a mobilizaçáo cognitiva é considerada como o principal fator determinante do engajamento político, já que os resultados demonstraram que, em consonância com a escala de racionalidade referente ao envolvimento em partidos, os apartidários seriam os eleitores mais ativos politicamente, em todas as cinco modalidades de atuação analisadas. E em uma sequência decrescente, os partidários cognitivos comporiam o segundo perfil mais ativo; seguidos por partidários rituais; e, com menor intensidade de ação política, os independentes apolíticos. Além disso, o conjunto de resultados no capítulo é consoante, ainda, com o modelo de status social de Verba, Schlozman e Brady (1995) e, ao abordar especificamente ações não convencionais, com a afirmação de Opp (2009), visto que a participaçáo é possível de acordo com os recursos disponíveis aos indivíduos.

Em se tratando de atividades que mantêm o papel dos partidos políticos como instituiçóes centrais ao processo democrático, Dalton concentra sua análise sobre a seleção dos candidatos, a estruturação do debate político, a organização das eleiçóes e a administração do governo. Utilizando dados 
decorrentes de pesquisas do ANES realizadas entre 1952 e 2008, o autor identificou - por meio de um índice de afeto dos eleitores aos partidos - as imagens que os diferentes grupos possuem acerca dos próprios partidos e do sistema partidário norte-americano ${ }^{2}$. Os resultados apontam o destaque dos apartidários enquanto eleitores mais propensos a avaliar os candidatos e os partidos com base nas políticas atuais e no desempenho de cada um, bem como o preocupante desengajamento dos menos mobilizados cognitivamente, cada vez mais distantes do campo político.

O autor propóe, ainda, uma discussão acerca dos diferentes resultados, em termos de mobilização cognitiva, advindos de eleiçóes presidenciais e para o Congresso norte-americano, considerando que nos Estados Unidos a primeira eleição teve grande repercussáo e destaque na mídia e na internet, ao passo que a segunda se caracterizou por menor estímulo em termos de propagação de informaçóes. Seus resultados demonstram empiricamente a forma como os diferentes eleitores norte-americanos estruturam seus votos, com destaque aos apartidários, que levam menos em consideração os aspectos partidários das imagens dos candidatos e enfatizam majoritariamente os critérios relacionados às propostas políticas.

O último capítulo analítico acerca dos eleitores dos Estados Unidos se dedica à avaliação da decisão eleitoral. Dados históricos da ANES referentes ao período entre 1964 e 2004 apontam que a maior parte do eleitorado daquele país decide seu voto durante o período em que são realizadas as convençóes partidárias, no início do processo eleitoral. Entretanto, dados recentes revelam que entre os partidários, rituais e cognitivos, as convençóes mantêm sua influência, ao passo que os apartidários retardariam sua decisão até o momento mais próximo das eleiçôes - o que lhes permitiria melhores condiçôes de

20 índice é composto por seis categorias, que descrevem os distintos padrões de relacionamento dos norte-americanos com seu sistema partidário, bem como permite visualizar alterações do comportamento dos eleitores ao longo do tempo. Tais categorias são: manifestação positiva de afeto (quando ambos os partidos - Republicano e Democrata - recebem comentários positivos pelo eleitor); manifestação polarizada (quando são manifestadas opiniões divergentes sobre os partidos, positiva para um e negativa ou o outro); de preferência (marcada pelo posicionamento positivo com relação a um partido e neutro com relação a outro ou neutro quanto a um partido e negativo para o outro); neutra (quando ambos os partidos são destinatários de elogios e críticas ou os comentários são neutros - sem menção positiva ou negativa); negativa (no caso de posicionamento crítico frente a ambos os partidos); e a ausência de comentários ou de menções positivas el ou negativas aos partidos. 
analisarem e avaliarem as possibilidades eleitorais, no sentido de escolherem o candidato ou partido cujas premissas e propostas se alinhariam mais adequadamente às suas expectativas. Desta forma, o posicionamento de tais eleitores seria, segundo Dalton, o mais próximo do que se espera de um bom cidadáo democrático.

Chancelado por resultados que lhe permitem validar a tese de que o eleitorado norte-americano pode ser classificado em uma escala de sofisticação que avança desde independentes apolíticos até apartidários, Dalton destaca, em capítulo específico, uma comparação entre tais resultados e dados de um conjunto de países predominantemente europeus composto por democracias com diferentes características: umas tradicionais, outras da terceira onda de democratizaçáo e, ainda, algumas pós-comunistas ${ }^{3}$. No livro, percebe-se a consciência de que pesquisar a questáo do partidarismo para além dos Estados Unidos exige atenção pelo fato de que em alguns países ser partidário é visto como algo negativo e que, de maneira semelhante, ser independente náo necessariamente possui a mesma conotação verificada no cenário norte-americano; além disso, os resultados decorrentes de surveys aplicados no decorrer da primeira década do século XXI ressaltaram o crescimento do padrão de volatilidade entre tais democracias, em um movimento não linear e permeado por fatos históricos, políticos e econômicos de cada nação.

Dalton identificou a ascensão de novos partidos, o que se deve, ainda que parcialmente, ao desalinhamento partidário verificado nas democracias analisadas. Cabe destacar que Dalton afirma ser impressionante a semelhança entre os resultados encontrados de declínio do partidarismo em naçóes com diferentes sistemas eleitorais, com números de partidos e padróes de clivagens partidárias diversos, em especial com relação à cultura política do eleitorado.

Diante da aplicabilidade de sua tipificação eleitoral entre os norte-americanos, expandida a eleitores do conjunto de países anteriormente mencionados, as conclusóes de Dalton podem ser resumidas, na concepção do autor desta resenha, nos seguintes pontos: [1] o desengajamento partidário crescente não é de todo negativo, já que nem todos os eleitores não partidários são

3 O conjunto de paises analisados compreende: Suécia, Portugal, Dinamarca, Noruega, Holanda, Israel, Grécia, Áustria, Finlândia, Suiça, França, Espanha, Reino Unido, Alemanha, Bélgica, Irlanda, Itália, Austrália, Canadá, Japão e Nova Zelândia. 
independentes apolíticos e aqueles identificados como apartidários representam uma implicação positiva ao processo eleitoral e à democracia; [2] apesar de tal constatação, ainda há razóes para se ter cautela ao fazer análises sobre não partidários, uma vez que aqueles que gozam de baixa mobilizaçáo cognitiva possuem maior probabilidade de serem mal informados, de esboçarem opinióes políticas inconsistentes e de serem mais suscetíveis aos apelos de políticos carismáticos; [3] a mobilização cognitiva se destaca como fator mais explicativo para o engajamento político do que o partidarismo, o que se evidencia pelo forte relacionamento entre as modalidades convencionais e contestatórias (como o comparecimento eleitoral, as açóes diretas não eleitorais e o protesto) e a medida combinada entre escolaridade e interesse por política; e [4] os partidos políticos devem se preocupar cada vez mais com o desenvolvimento das campanhas eleitorais, pois o diagnóstico de Dalton é de que os programas e as plataformas eleitorais têm contribuído para a decisão do voto de partidários cognitivos (em alguma medida) e de apartidários (de maneira expressiva).

Em suma, a expansão dos níveis de escolarização e o maior acesso à informação sobre política se destacam entre os fatores que têm produzido um processo de mobilizaçáo cognitiva que amplia as habilidades políticas e os recursos do cidadáo médio. Consequentemente, menos pessoas devem confiar em lealdades partidárias passadas pelos pais, mediante processos de socialização e reforçadas pelo apoio habitual aos partidos. Em vez disso, mais eleitores de democracias consolidadas se aproximam da política com uma maior capacidade de julgar os candidatos e as questóes políticas sem dependência de lealdades partidárias. Nesses termos, a mobilizaçáo cognitiva demonstra potencial para mudar o processo eleitoral devido à elevação do número de eleitores que são capazes de emitir julgamentos, independentemente dos candidatos e das questóes do momento, quando fizerem suas escolhas eleitorais.

Ademais, dois últimos pontos da obra merecerem destaque. Em primeiro lugar, Dalton destaca a relevância do eleitor apartidário como ideal a ser perseguido pelas democracias. Tal afirmação é considerada preocupante pelo autor desta resenha, uma vez que se o aumento da sofisticaçáo política náo atinge os independentes apolíticos que se encontram na base do processo - distantes dos atalhos informacionais que os partidos e o conhecimento político são capazes de oferecer -, pois esse grupo de eleitores se encontrará cada vez mais afastado do ambiente político, quanto mais evoluírem, na escala de racionalidade dos 
perfis, os demais eleitores. Em segundo lugar, é preciso considerar a novidade na classificação do eleitorado, em razão da proposta analítica de tipificação em quatro perfis distintos, o que supera os binarismos entre náo partidários e partidários e entre eleitores alienados e sofisticados.

É de entendimento deste resenhista que a teoria da mobilizaçáo cognitiva e a tipificação eleitoral em perfis cognitivos de Russell J. Dalton em "The apartisan American" devem ser interpretadas com parcimônia, considerando a discussão acerca de sua aplicabilidade em contextos diferentes do norte-americano e europeu e tomado o conjunto de países analisados enquanto bloco. Nesse sentido, esta resenha volta-se exclusivamente aos resultados dos primeiros testes realizados no âmbito do projeto de pesquisa "Os determinantes do ativismo partidário e do comparecimento eleitoral na América Latina” envolvendo o modelo testado por Dalton, uma vez que identifica, em conjunto com colaboradores, que entre os brasileiros os resultados são bastante distintos daqueles encontrados por Dalton, tanto no plano da composição do eleitorado quanto em seus correlatos comportamentais e atitudinais (BORBA; RIBEIRO; GIMENES, 2013). De maneira semelhante, a escolaridade não se apresentou como preditora de duas distintas modalidades de partidarismo entre o eleitorado latino-americanos: participação em reunióes de partidos ou movimentos políticos e simpatia partidária (GIMENES; BORBA; RIBEIRO, 2014). Considerando a composição histórica, política e social do Brasil e dos demais países latino-americanos, visto que muitos destes foram redemocratizados por ocasiâo da "terceira onda" (HUNTINGTON, 1994), a expansão da análise realizada entre o eleitorado nacional ao conjunto de países da América Latina pode revelar divergências com relação aos achados empíricos do autor norte-americano, devido à diferenciaçáo do contexto latino-americano no que tange aos percentuais de eleitores com alta escolarizaçáo, os quais se encontram muito abaixo daqueles identificados em democracias consolidadas.

Recebido em: 15.11.2013

Aprovado em: 22.09.2014

4 Desenvolvido com apoio financeiro do CNPq/CAPES.

5 Foram analisados os dados da última onda de "Surveys do Latin American Public Opinion Project (LAPOP)", referentes ao ano de 2012, para os seguintes paises: Argentina, Belize, Bolivia, Brasil, Chile, Colômbia, Costa Rica, Equador, El Salvador, Guatemala, Guiana, Honduras, Jamaica, México, Nicarágua, Panamá, Panamá, Peru, República Dominicana, Suriname, Trinidad e Tobago, Uruguai e Venezuela. 


\section{Referências}

BORBA, J.; RIBEIRO, E. A.; GIMENES, E. R. Os apartidários brasileiros: bases sociais, atitudinais e comportamentais do eleitorado brasileiro. In: CONGRESO LATINOAMERICANO DE CIENCIA POLÍTICA, 7., Bogotá, 2013.

DALTON, R. J. Independents and American elections. In: HERSHEY, M. (Ed.). CQ Guide to Political Parties. Washington, DC: CQ Press, 2014a. p. 262-270.

Interpretating partisan dealignment in Germany. German Politics, 2014b, p. 1-11.

Disponível em: <http://www.socsci.uci.edu/ rdalton/archive/Germanpolitics2014.pdf>. Acesso em: 5 nov. 2013.

Partisan dealignment and voting choice. In: PADGETT, S. et al. Developments in German Politics IV. Londres: Macmillan, 2014c. p. 57-77.

The apartisan American: dealignment and changing electoral politics. Washington, DC: Sage, 2013.

DALTON, R. J.; FARRELL, D.; MCALLISTER, I. Political parties and democratic linkage. Oxford: Oxford University Press, 2011.

GIMENES, E. R.; BORBA, J.; RIBEIRO E. A. Os determinantes do ativismo partidário na América Latina. In: CONGRESO WAPOR LATINOAMÉRICA: OPINIÓN PÚBLICA, CRISIS DE REPRESENTACIÓN Y NUEVAS FORMAS DE PARTICIPACIÓN, 6., Santiago, 2014.

HUNTINGTON, S. A terceira onda: a democratização no final do século XX. São Paulo: Ática, 1994.

INGLEHART, R. The silent revolution. Princeton: Princeton University, 1977.

NORRIS, P. Political activism: new challenges, new opportunities. In: BOIX, C.; STOKES, S. C. The Oxford handbook of comparative politics. Oxford: Oxford University Press, 2007. p. 628-652.

Critical citizens: global support for democratic governance. Oxford: Oxford University Press, 1999.

OPP, K. D. Theories of political protest and social movements: a multidisciplinary introduction, crítique, and synthesis. Londres: Routledge, 2009.

VERBA, S.; SCHLOZMAN, K. L.; BRADY, H. E. Voice and equality: civic voluntarism in American politics. Cambridge: Harvard University Press, 1995. 